\title{
Identification of RPL5 and RPL10 as novel diagnostic biomarkers of Atypical teratoid/ rhabdoid tumors
}

Yanming Ren ${ }^{1 \dagger}$, Chuanyuan Tao ${ }^{1 \dagger}$, Xiliang Wang ${ }^{2}$ and Yan Ju ${ }^{1 *}$ (D)

\begin{abstract}
Background: Rhabdoid tumors (RTs) are aggressive tumors that occur most frequently in children under 2 years old, which often invade kidney (KRTs) and Center Nervous System, named Atypical teratoid/rhabdoid tumors (AT/ RTs). RTs often progress fast and lead to a high lethality. RTs have a low incidence, we can hardly accumulate enough samples to elicit the diagnosis. More importantly, histologically, RTs present a host of neural, epithelial, mesenchymal, or ependymal patterns, which makes them rather variable and difficult to diagnose. Molecularly, RTs are diagnosed mainly on the lack of SMARCB1/INI1 protein expression, which, on the one hand, accounts for $75 \%$ of RTs, on the other hand, loss of expression of SMARCB1 is not exclusive to RTs. So, there is a need to find more accurate diagnose markers of RTs.
\end{abstract}

Methods: In this study, we analyzed 109 samples including AT/RT, KRT and corresponding normal samples downloaded form NCBI GEO database. First, we identified the differentially expressed IncRNAs and PCGs in AT/RT, KRT and corresponding normal samples. Second, we evaluated the co-expression relationship between IncRNA and PCG, and defined four types of the dysregulated PCG-IncRNA pairs. Third, we compared the differentially expressed genes, the dysregulated PCG-IncRNA pairs and commonly known cancer genes, we get potential diagnostic markers. Then, the potential diagnostic markers were subjected to Receiver operating characteristic (ROC) analysis to assess the diagnostic accuracy. Importantly, differential expression of the marker genes in different tumors was shown to distinguish AT/ RT and KRT from other pediatric tumors specifically.

Results: We compared the expression profiles between 47 AT/RTs, 31 KRTs, 8 normal brain samples, and 23 normal kidney samples. After applying a stringent set of criteria on the gene expression profiles, we identified 3667 PCGs and 81 IncRNAs differentially expressed in AT/RT, 3809 PCGs and 34 IncRNAs differentially expressed in KRT tissues. Next, we compared the three sets(AT/RT versus control brain samples, KRT versus control kidney samples, and AT/RT versus KRT) of differentially expressed IncRNAs and PCGs, 491 PCGs and 2 IncRNAs appeared in all three sets. We examined the correlation of the expression levels of these genes in the 'three-set overlap' group and identified four types of dysregulated IncRNAs and PCGs. By compared these genes to the well-known cancer driver genes, 19 PCGs were selected as potential candidates of diagnostic markers. Filtered with the number of the corresponding co-expressed IncRNA (namely "degree"), eight PCGs with more than five IncRNAs in the 'three-set overlap' group were selected as candidate diagnostic markers. Among them, RPL5 and RPL10 exhibited high sensitivity and specificity in diagnosis of AT/RT and KRT. However, when these two genes were used to distinguish AT/RT and KRT from other pediatric tumors, only AT/RT can be distinguished from medulloblastoma.

\footnotetext{
*Correspondence: jvyan@scu.edu.cn

†Yanming Ren and Chuanyuan Tao contribute equally to this paper

1 Department of Neurosurgery, West China Hospital of Sichuan University,

No. 37 Guo Xue Xiang, Chengdu, Sichuan, China

Full list of author information is available at the end of the article
}

(c) The Author(s) 2018. This article is distributed under the terms of the Creative Commons Attribution 4.0 International License (http://creativecommons.org/licenses/by/4.0/), which permits unrestricted use, distribution, and reproduction in any medium, provided you give appropriate credit to the original author(s) and the source, provide a link to the Creative Commons license, and indicate if changes were made. The Creative Commons Public Domain Dedication waiver (http://creativecommons.org/ publicdomain/zero/1.0/) applies to the data made available in this article, unless otherwise stated. 
Conclusions: Our study mined existing GEO datasets for novel diagnostic markers associated with Rhabdoid tumors, and identified RPL5 and RPL10 as potential diagnostic markers for AT/RT. These two biomarkers may be used as supplementary biomarkers to canonical diagnostic tools such as biopsy and immunohistochemistry.

Keywords: Atypical teratoid/rhabdoid tumors, Kidney rhabdoid tumors diagnosis, Bioinformatics, Dysregulation, Biomarker

\section{Background}

Rhabdoid tumors (RTs) are aggressive tumors that occur most frequently in children under 2 years old. RTs often occur in the kidney (KRTs) or the central nervous system (CNS), which are termed Atypical teratoid/rhabdoid tumors (AT/RTs). Extracranial RTs were first recognized as a physiological entity nearly 40 years ago [1]. Later, Haas and colleagues introduced the term rhabdoid in describing KRT, due to the close histological resemblance of the tumor cells to rhabdomyoblasts, although subsequent studies have not confirmed a myogenic origin of these tumor cells [2]. In 1987, AT/RT was recognized as a discrete clinical entity based on pathologic and genetic characteristics [3]. Prior to that, it had been mostly classified as either medulloblastoma, primitive neuroectodermal tumor, or choroid plexus carcinoma. Following this description, the World Health Organization (WHO) began to classify AT/RT as an embryonal grade IV neoplasm in 1993 [4].

Epidemiologic studies of RT have been limited by the fact that this is a rare disease. So far there have been only a handful of epidemiologic reports. In a study conducted in the UK, 106 children under 15 years old were diagnosed with extracranial RT in the UK between in a period of nearly 20 years [5], resulting in an age-standardized annual incidence of 0.6 per 1 million children. In the US, several studies observed that AT/RT accounted for $1-2 \%$ in pediatric brain tumors, and for $4.4 \%$ of CNS tumors in children aged zero to 5 years [6-9]. Two more recent surveys conducted in China draw consistent results of a prevalence of AT/RT at approximately $5 \%$ in pediatric CNS tumors, which is comparable to that in the US study.

Aside from low incidence rate, there are other factors that poses challenges to the diagnosis and treatment of RTs. Histologically, RTs manifest several characteristic features, including eosinophilic cytoplasm, large nucleoli, and filamentous cytoplasmic inclusions. The tumors may present a host of neural, epithelial, mesenchymal, or ependymal patterns, which makes them rather variable and difficult to diagnose [10]. Moreover, RTs often progress fast and lead to a high lethality. In the UK study of extracranial RT, 1-year survival was 31\% [5]. The patients usually suffers from metastasis and, to make things worse, the young age of patients limits use of radiotherapy. In an early report of 22 cases of KRTs in children, metastases were found in $82 \%$ of cases, either at diagnosis, or developing from 2 weeks to 9 months after diagnosis. Only two patients eventually survived, both with localized disease (stage II) [11]. Therefore, early diagnosis of this formidable disease is of key importance and in urgent demand.

Currently RTs are diagnosed mainly on immunohistochemistry (IHC) results, specifically, the lack of SMARCB1/INI1 protein expression, or less frequently, that of SMARCA4/BRG1 protein expression [4]. Initial genetic studies suggested that approximately $75 \%$ of RTs are characterized by biallelic inactivation of the SMARCB1 locus, which indicated a sensitivity of close to $75 \%$ [12]. However, loss of expression of SMARCB1 is not exclusive to RTs, but also has been observed in other types of cancers, including chordoma, epithelioid sarcoma, cribriform neuroepithelial tumor, and medullary renal cell carcinoma [13-19]. Together, these lines of evidence suggest that SMARCB1 expression alone is neither sufficiently sensitive nor specific for diagnosing RTs. Moreover, in particular for CNS AT/RTs, another severe limitation in clinical diagnosis is the potential misdiagnosis as medulloblastomas (MBs) or primitive neuroectodermal tumors (PNETs), owing to the close histological resemblance of the rhabdoid cells and neuroepithelial tissue in these tumors $[3,20]$. In conclusion, diagnostic markers with improved sensitivity and specificity are needed to complement the current practice, to the end of developing a comprehensive diagnostic strategy with enhanced sensitivity and precision.

In this study, we set out to identify diagnostic markers for RTs by employing a molecular profiling approach. Protein coding genes (PCGs) and long non-coding RNAs (lncRNAs) showing aberrant expression in AT/ RT and KRT cases were identified, respectively, and the co-expression between these significantly dysregulated genes was evaluated. Through further comparison of differentially expressed genes, the dysregulated PCGlncRNA pairs, and commonly known cancer genes, candidate diagnostic markers for AT/RT were identified and subjected to Receiver Operating Characteristic analysis to assess the performance of these candidates. Two PCGs, RPL5 and PRL10, exhibited high sensitivity and specificity not only in diagnosis of AT/RT but also 
differential diagnosis of AT/RT and KRT, as therefore show considerable promise for AT/RT diagnosis, and warrants further investigation.

\section{Methods}

\section{Data analysis}

The raw data were downloaded from the NCBI GEO database (GSE15641, GSE11482, GSE30946, GSE64019, GSE28026, GSE35493, GSE64019, GSE70421, GSE35493). The limma package was used to deal with the raw data in CEL format, with MAS5 algorithm, to quantify expression level and to identify the difference of gene expression. The biomaRt package was used to convert the probe ID to Ensembl ID. Genes were categorized as "protein coding" and "long non-coding" based on an Ensembl annotation file in the GTF format. Among non-coding genes, rRNAs, tRNAs, miRNAs, snoRNAs and other known classes of RNAs were excluded, and lncRNAs were defined as all non-coding genes longer than 200 nucleotides and not belonging to other RNA categories.

\section{Pearson's correlation coefficient}

Pearson's correlation coefficient (PCC) was calculated by in-house R-scripts and was utilized to evaluate the coexpression relationship between lncRNA and PCG. Coexpressed pairs were defined with a cutoff of $|\mathrm{PCC}| \geq 0.7$ and $\mathrm{P}<0.001$.

\section{Data visualization}

Unsupervised hierarchical clustering was done by $\mathrm{R}$ software (version 3.3.2, http://www.r-project.org/). The receiver operating characteristic (ROC) and the area under the ROC curves (AUC) values were obtained from the pROC package. Unless otherwise specified, data were analyzed and visualized using $\mathrm{R}$ software (version 3.3.2).

\section{Enrichment analysis}

For enrichment analysis to explore their biological effects, PCGs were analyzed using the clusterProfiler package. The GO terms and KEGG pathways with $p$ values or FDR of $<0.05$ were considered as significantly enriched function annotations.

\section{Differential RPL5/10 expression analysis across Affymetrix datasets}

We downloaded GSE85217 and GSE2712 from GEO dataset. GSE85217 contains 762 medulloblastoma patients expression data, and GSE2712 contains 18 Wilms' tumors and 14 clear cell sarcoma of the kidney. The former used Affymetrix Human Gene 1.1 ST Array, the latter used Affymetrix Human Genome U133A Array. So in order to make the data comparable, we used the Array Generation based gene Centering (AGC) method to compare the expression value of RPL5/10 between different datasets [21]. The AGC method scaled datasets with a scaling factor that is defined based on the housekeeping genes.

\section{Results}

Transcriptome expression profiles in AT/RT, KRT and normal samples

We started by comparing the expression profiles between 47 AT/RTs, 31 KRTs, 8 normal brain samples, and 23 normal kidney samples (sample list in Additional file 1: Table S1). Between tumor and normal samples, expression of lncRNAs showed greater level of alteration in AT/ RT or KRT (Fig. 1a, b) than that of PCGs (Fig. 1d, e), suggesting a specific expression pattern of lncRNAs in these tumors. However, comparing with KRT, both lncRNAs and PCGs showed weaker changes in expression levels in AT/RT (Fig. 1c, f), suggesting that resemblance in the expression profiles of tumors of RTs and its subtype, AT/ RT.

\section{Differentially expressed IncRNAs and PCGs in AT/RT, KRT and normal samples}

After applying a stringent set of criteria on the gene expression profiles, we identified groups of lncRNAs and PCGs differential expressed between tumor and normal tissue samples $(\mathrm{p}=0.00001$ and fold change $(\mathrm{FC})=2$ for KRT vs. kidney and AT/RT vs. brain, $\mathrm{p}=0.001$ and fold change $=2$ for KRT vs. AT/RT). In total, we identified 3667 PCGs and 81 lncRNAs differentially expressed in AT/RT, with 988 up-regulated and 2679 down-regulated PCGs and 14 up-regulated and 67 down-regulated lncRNAs in the tumor samples (Table 1). Notably, there were more than twice as many down-regulated genes as upregulated ones. Between KRT and normal samples, 3809 PCGs (1963 up-regulated and 1846 down-regulated) and 34 lncRNAs (14 and 20, respectively) showing aberrant expression in KRT tissues (Table 1). As differentially expressed genes between KRT and AT/RT, 3381 PCGs and 91 lncRNAs showed significantly altered expression levels. Among these genes we identified 2568 upregulated and 813 down-regulated PCGs along with 59 up-regulated and 32 down-regulated lncRNAs (Table 1). Of note, there were approximately three times as many down-regulated genes as up-regulated ones, suggesting the significance of these genes in differentiating RTs and its subtype AT/RT.

A hierarchical cluster analysis of differentially expressed lncRNAs and PCGs showed that samples derived from AT/RT or KRT were well distinguished from corresponding normal ones based on the expression patterns of these genes (Fig. 2). This clear distinction between tumor and control samples suggests the highly 


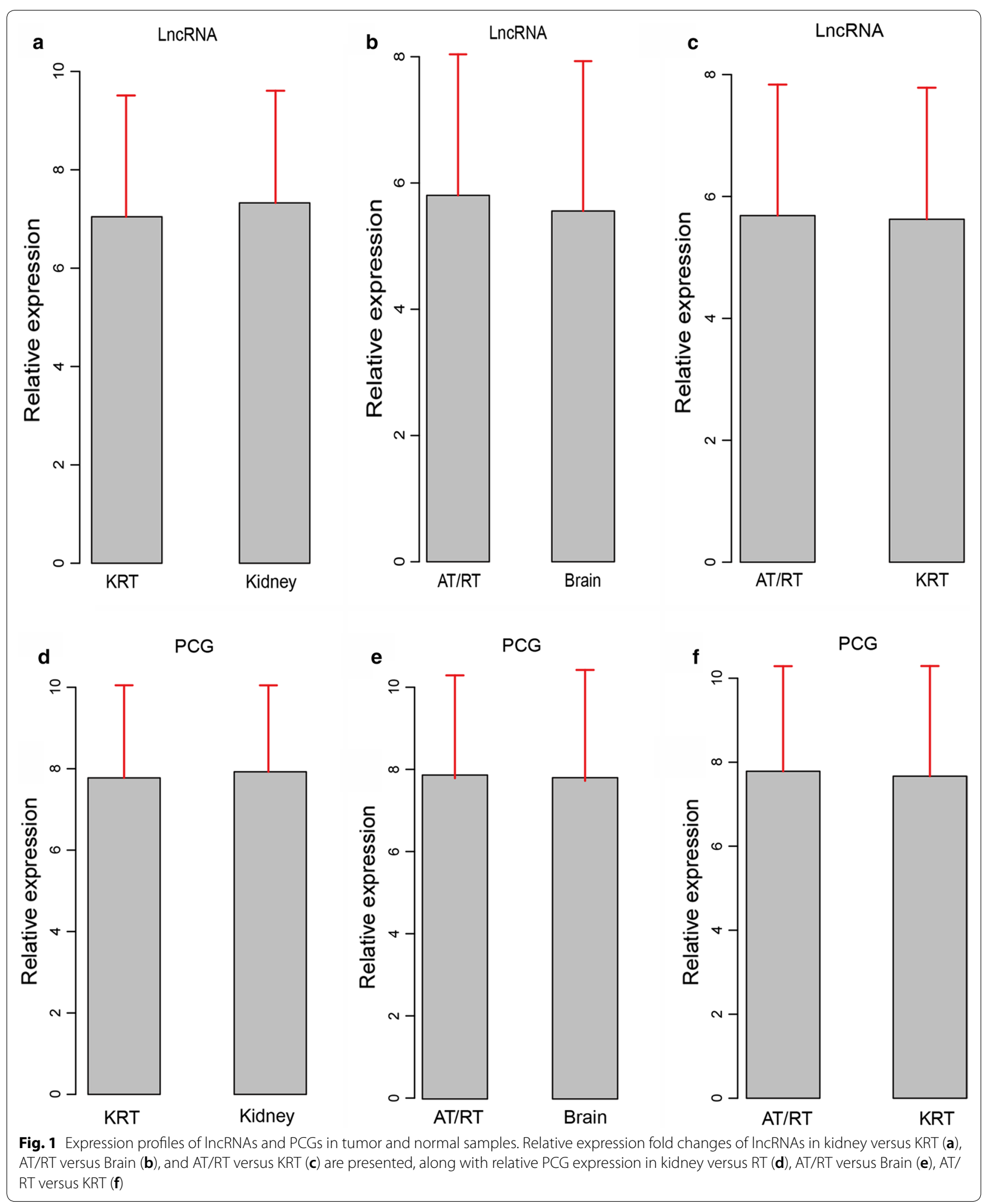


Table 1 A summary of differentially expressed IncRNAs and PCGs between AT/RT, KRT and the corresponding normal control samples

\begin{tabular}{|c|c|c|c|c|c|c|}
\hline & \multicolumn{2}{|c|}{ AT/RT vs. Brain } & \multicolumn{2}{|c|}{ KRT vs. Kidney } & \multicolumn{2}{|c|}{ KRT vs. AT/RT } \\
\hline & Up & Down & Up & Down & Up & Down \\
\hline PCG & 988 & 2679 & 1963 & 1846 & 2568 & 813 \\
\hline IncRNA & 14 & 67 & 14 & 20 & 59 & 32 \\
\hline
\end{tabular}

AT/RT atypical teratoid/rhabdoid tumors, KRT kidney rhabdoid tumors)

specific nature of the dysregulation of these genes to the corresponding diseases.

Next, we performed pathway enrichment analysis on differentially expressed PCGs to gain insights into pathways potentially implicated in this disease. A total of 72 pathways were significantly enriched (adjusted $\mathrm{p}$ value $<0.05)$. As show in Fig. 3a, many of the differentially expressed PCGs in AR/RT play roles in neural signaling pathways, such as retrograde endocannabinoid signaling (endocannabinoids serve as retrograde messengers at synapses in various regions of the brain [22, 23]), dopaminergic synapse (Dopamine is an important and prototypical slow neurotransmitter in the mammalian brain, where it controls a variety of functions including locomotor activity, motivation and reward, learning and memory, and endocrine regulation [24, 25]), glutamatergic synapse (Glutamate is the major excitatory neurotransmitter in the mammalian central nervous system $[26,27])$, "Cholinergic synapse" (Acetylcholine is a neurotransmitter widely distributed in the central nervous system [28, 29]), GABAergic synapse (Gamma aminobutyric acid (GABA) is the most abundant inhibitory neurotransmitter in the mammalian central nervous system $[30,31])$. Differentially expression PCGs in KRT, on the other hand, were enriched mainly in processes related to RNA transcription and protein translation, such as RNA transport, ribosome, and spliceosome (Fig. 3b). As for the differentially expressed PCGs between AT/RT and KRT, 19 pathways were enriched significantly (adjusted $\mathrm{p}$ value $<0.05)$. Among these enriched pathways, some overlapped with ones enriched from dysregulated genes in KRT (Fig. 3b). In addition, there were also a considerable number of pathways involved in neurodegenerative diseases, such as Huntington's disease, Alzheimer's disease, and Parkinson's disease (Fig. 3c). As AT/RT and KRT are both subtypes of RT, the overlapping enriched pathways may represent common pathological mechanisms in both subtypes, while the more CNS-specific pathways may be specific to AT/RT.

Next, we compared the three sets of differentially expressed lncRNAs and PCGs, namely those showing significantly different expression levels between AT/RT versus control brain samples, KRT versus control kidney samples, and AT/RT versus KRT. Venn diagrams were plotted for differentially expressed lncRNAs (Fig. 4a) and PCGs (Fig. 4b), and genes that appeared in all three sets (referred to as the 'three-set overlap' group) were selected. A total of 491 PCGs and 2 lncRNAs fell in this group, which served as the pool for further screening of candidate markers for diagnosing AT/RT.

\section{Dysregulated network of differentially expressed features}

Following the identification of differentially expressed lncRNAs and PCGs in AT/RT and KRT, we examined the correlation of the expression levels of these genes in the 'three-set overlap' group. A Pearson's correlation coefficient (PCC) was calculated for the expression levels of each pair of lncRNAs and PCGs across disease states. There were a total of 12,831 PCGs in the microarray profiles (denoted AllPCG in Table 2), among which 491 differentially expressed PCGs (denoted DiffPCG) (Fig. 4b) in all 'three-set overlap' group. Specifically, among these DiffPCGs we focused on the genes reported to be strongly associated with cancer (denoted CancerG). ("cancer genes" were cited from the report of Science [32]; "CancerG" for short, Additional file 2: Figure S1).

We identified four types of dysregulated lncRNAs and PCGs in Table 2. As listed, there were 69236, 18889, and 2773 dysregulated pairs of "AllPCG", "DiffPCG", and "CancerG" in AT/RT, respectively. The overwhelming majority type of the dysregulated pairs was Type I (Table 2) illustrating a massive loss in regulation of lncRNAs to PCGs in AT/RT patients. There were 45175, 13,765, and 1976 dysregulated pairs of "AllPCG", "DiffPCG", and "CancerG" in KRT vs. Kidney, respectively. It was the opposite that the overwhelming majority type of the dysregulated pairs was Type II in "AllPCG", "DiffPCG", and "CancerG", especially in "CancerG" (Table 2). In AT/RT vs. KRT There were 50,862, 7689, and 2011 dysregulated pairs of "AllPCG", "DiffPCG", and "CancerG", respectively, with the majority grouped into Type II (Table 2), showing vast difference of lncRNA dysregulation in AT/RT and KRT. The four types of dysregulated pairs may be one important reason for the aberrance of cancer cells, they may also play important roles in AT/RT or KRT, as well. 


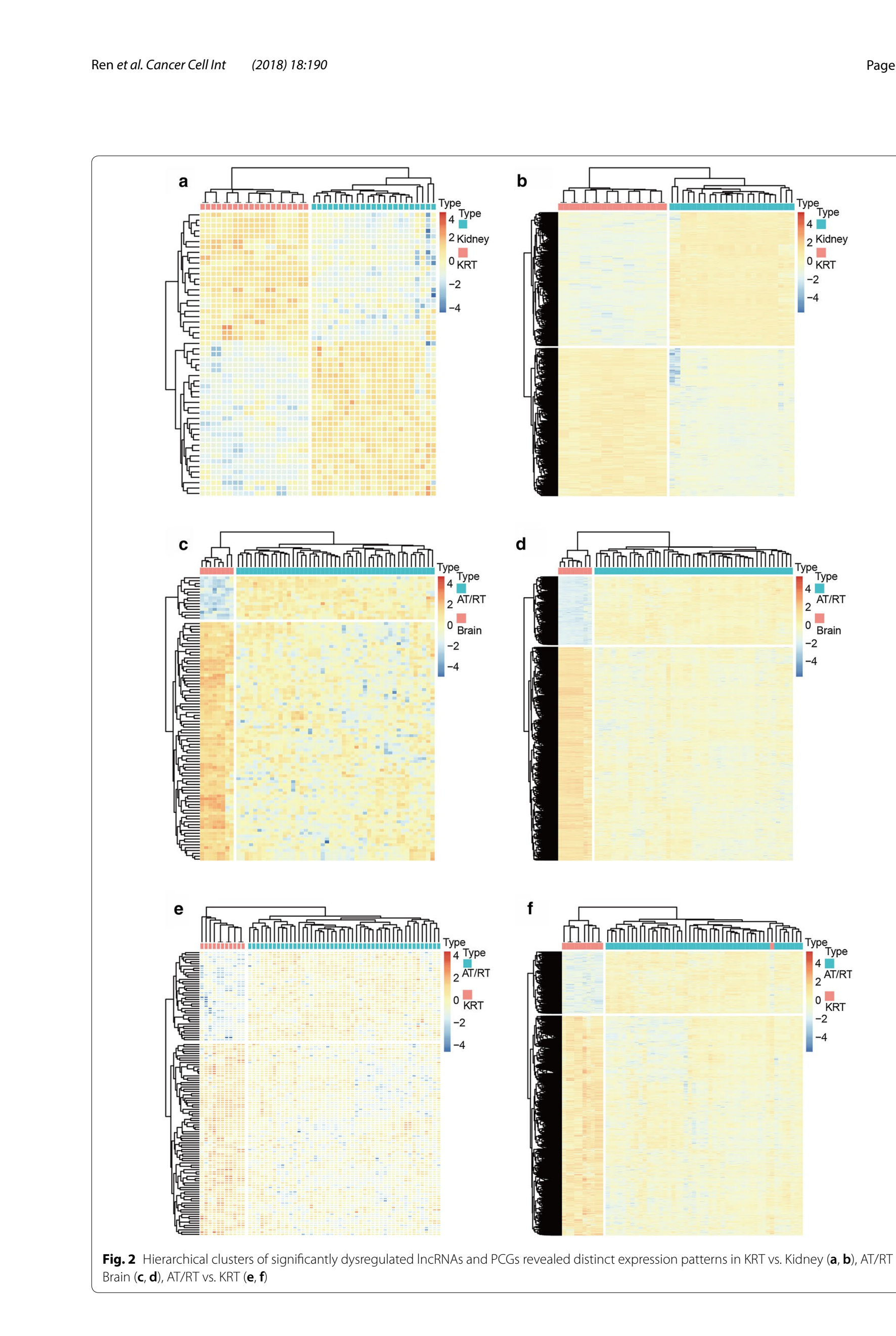




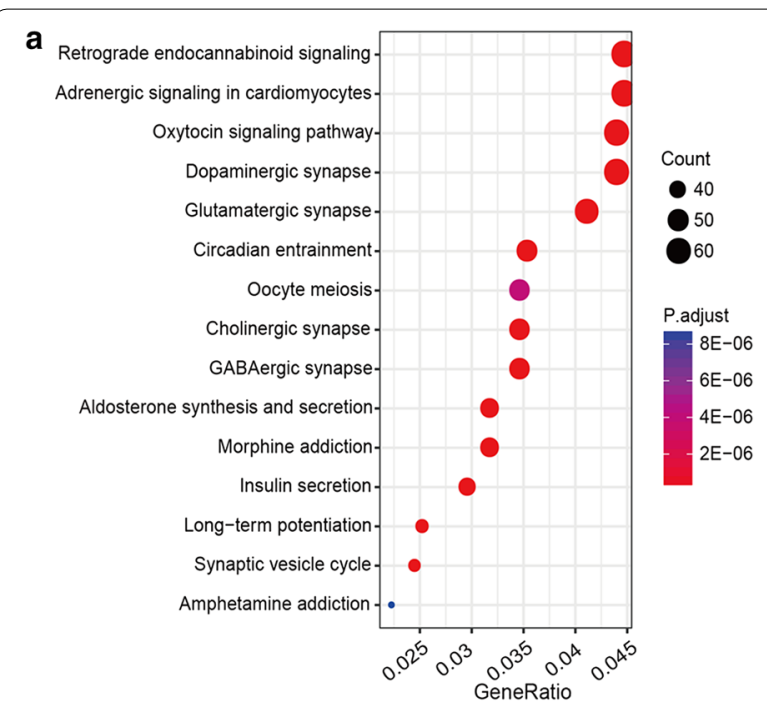

b

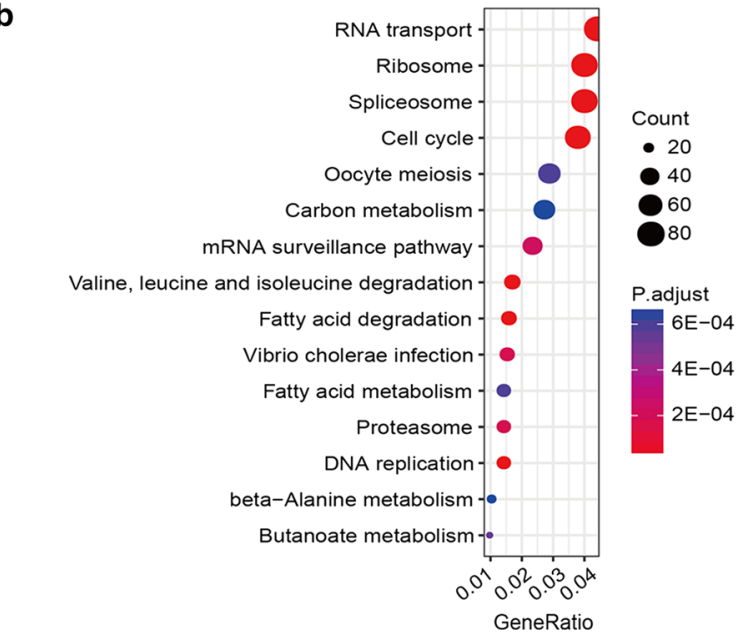

C

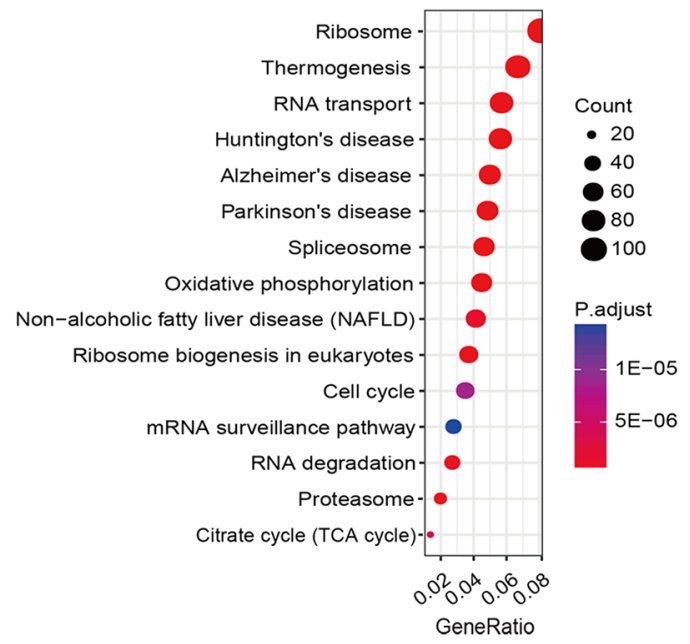

Fig. 3 KEGG pathway enrichment analysis of PCGs that showed significantly differential expression in AT/RT vs. Brain (a), KRT vs. Kidney (b), and KRT vs. AT/RT (c)
We focused on the "cancer genes" because they have been established to show high relevance in cancer initiation and development. We compared the dysregulated cancer genes in AT/RT vs. Brain, KRT vs. Kidney and AT/RT vs. KRT, there were 268 "cancer genes" dysregulated in all of the 'three-set overlap' group (Fig. 5a). Next, we checked whether those 268 genes were also differentially expressed in the 'three-set overlap' group. After comparing with the 491 DiffPCG (Fig. 4b), 19 PCGs were selected as potential candidates of diagnostic markers (Fig. 5b and Table 3). The dysregulated co-expression pairs were retrieved for these 19 PCGs, and the number of the corresponding co-expressed lncRNA (namely "degree") was showed in Table 4, where a high number is indicative of the complexity of lncRNA regulation to which the corresponding PCG is subjected, and suggests a more central position in the co-expression network. Therefore, eight PCGs with more than five lncRNAs in the 'three-set overlap' group were selected as candidate diagnostic markers, including RPL5, RPL10, NONO, PBRM1, PCM1, PTEN, SF3B1, and ZMYM2. KEGG pathway and Gene Ontology enrichment analysis highlighted ribosome as the main convergence of these aberrantly expressed genes, strongly hinting at a significant role of dysregulation of ribosome-related functions and processes in AT/RT and KRT (Fig. 6).

\section{Diagnostic values of RPL5 and RPL10 in AT/RT and KRT}

To evaluate the performance of the eight candidate markers identified in the last section in diagnosing AT/RT and RT, ROC (Receiver operating characteristic) analysis was performed and the area under curve (AUC) served as the basis for selecting the most sensitive and specific candidates.

Two significantly deregulated cancer-related genes, RPL5 and RPL10, showed outstanding performance in the ROC analysis. As shown in Fig. 7, in KRT versus normal kidney samples, AUC for RPL5 reached 1 (95\% CI 1-1), with both sensitivity and specificity level at 1 (Fig. 7a). Also, the AUC of RPL10 reached 0.97 (95\% CI $0.924-1$ ), with a sensitivity level of 0.913 and specificity level of 1, respectively (Fig. 7b). Moreover, high levels of diagnostic values were also observed for both genes in AT/RT. AUCs were 0.997 (95\% CI 0.99-1) and 0.989 (95\% CI 0.969-1) for RPL5 and RPL10, respectively, with sensitivity levels of 0.979 (RPL5) and 0.936 (RPL10), and a specificity level of 1 for both genes (Fig. 7c, d).

More importantly, both genes were powerful indicators for distinguishing AT/RT from KRT. When comparing expression profiles in AT/RT samples with those in KRT samples, AUC for RPL5 was 0.950 (95\% CI 0.897-1) with sensitivity and specificity levels of 0.83 and 1 , respectively (Fig. 7e). AUC for RPL10 was 0.973 (95\% CI 0.933-1) 


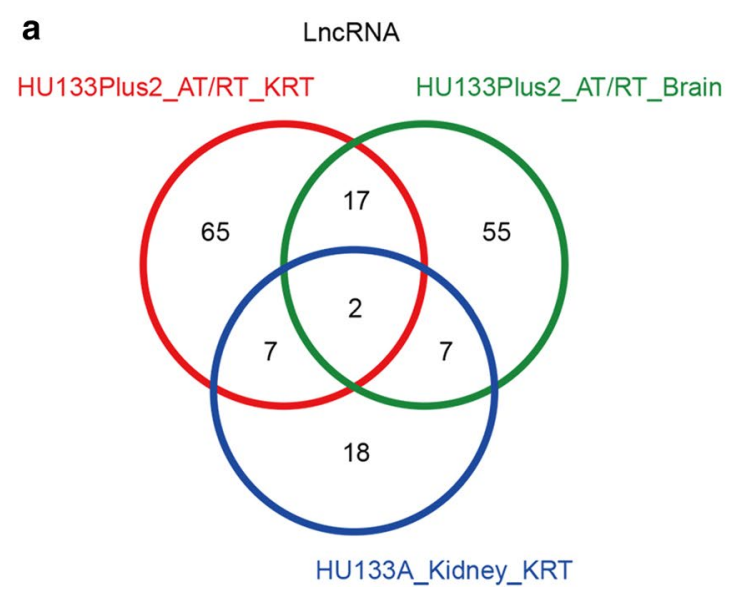

b

PCG

HU133Plus2_AT/RT_KRT HU133Plus2_AT/RT_Brain

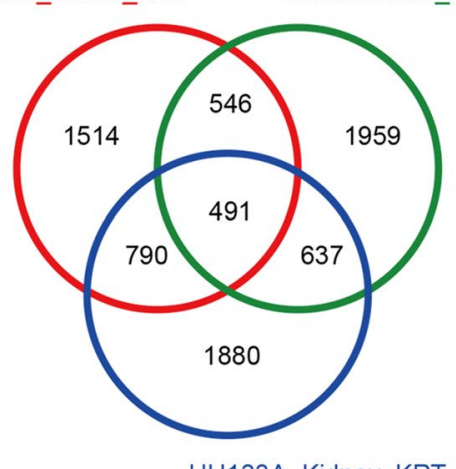

Fig. 4 Differentially expressed IncRNAs (a) and PCGs (b) significantly dysregulated in AT/RT vs. Brain, KRT vs. Kidney and KRT vs. AT/RT

Table 2 Four types of dysregulated pairs of IncRNA-PCG in AT/RT vs. Brain, KRT vs. Kidney and AT/RT vs. KRT

\begin{tabular}{|c|c|c|c|c|c|}
\hline \multicolumn{6}{|c|}{ AT/RT vs. Brain } \\
\hline Brain & AT/RT & Type & AllPCG & DiffPCG & CancerG \\
\hline Yes & No & 1 & 66,125 & 18,651 & 2629 \\
\hline No & Yes & $\|$ & 3059 & 232 & 138 \\
\hline Positive & Nagetive & III & 16 & 4 & 2 \\
\hline Nagetive & Positive & IV & 36 & 2 & 4 \\
\hline \multicolumn{6}{|c|}{ KRT vs. Kidney } \\
\hline Kidney & KRT & Type & AllPCG & DiffPCG & CancerG \\
\hline Yes & No & 1 & 16,408 & 6259 & 675 \\
\hline No & Yes & $\|$ & 28,350 & 7371 & 1284 \\
\hline Positive & Nagetive & III & 260 & 100 & 12 \\
\hline Nagetive & Positive & IV & 157 & 35 & 5 \\
\hline \multicolumn{6}{|c|}{ AT/RT vs. KRT } \\
\hline AT/RT & $\mathrm{KRT}$ & Type & AllPCG & DiffPCG & CancerG \\
\hline Yes & No & 1 & 5543 & 776 & 263 \\
\hline No & Yes & $\|$ & 45,245 & 6908 & 1742 \\
\hline Positive & Nagetive & III & 53 & 2 & 5 \\
\hline Nagetive & Positive & IV & 21 & 3 & 1 \\
\hline
\end{tabular}

Co-expressed pair were classified into four types, based on presence and type of regulation of the co-expression in the three sets of comparisons, namely (A) AT/ RT vs normal brain samples, (B) KRT vs normal kidney samples, and (C) AT/RT vs KRT samples. Type l: co-expressed pairs that were present in AT/RT (A), KRT (B), and AT/RT (C), and absent in normal brain samples (A), normal kidney samples (B), and KRT(C). Type Il: co-expressed pairs that were absent in AT/RT (A), KRT (B), and AT/RT (C), and was present in the corresponding control samples. Type III: co-expression pairs that were positively co-expressed in AT/RT (A), KRT (B), and AT/RT (C) and negatively co-expressed in the corresponding control samples. Type IV: co-expression pairs that were negatively co-expressed in AT/RT (A), KRT (B), and AT/RT (C) and positively co-expressed in the corresponding control samples

and also with high sensitivity (0.957) and specificity (1) (Fig. 7f). In other words, in the samples examined in this analysis, AT/RT and KRT could be accurately diagnosed based on expression levels of RPL5 and RPL10 (Additional file 3: Figure S2).

\section{RPL5 and RPL10 can be used to distinguish AT/RT from medulloblastoma}

To evaluate whether RPL5 and RPL10 can be used to distinguish AT/RT and KRT from other tumors, we compared the expression levels of RPL5 and RPL10 in RTs and other types of tumor. Compared with medulloblastoma, RPL5 and RPL10 were signifcantly upregulated in AT/RT, with fold changes of 1.25 and 1.5 ( $\mathrm{p}<0.001$, Fig. 8a, b), respectively. On the other hand, when compared with Wilms' tumor and clear cell sarcoma of the kidney, RPL5 and RPL10 were signifcantly downregulated in KRT (Fig. 8c, d). Together, these results suggest that RPL5 and RPL10 as promising diagnostic markers not only in distinguishing for AT/RT from normal tissues but also in from other types of pediatric tumors.

\section{Discussion}

Rhabdoid tumors are highly lethal cancers that most frequently observed in young children. Research into the diagnosis and treatment has been hampered by the rare nature of this disease despite its urgency. In a recent study, Chun et al. performed a molecular dissection of Malignant rhabdoid tumors (MRT, mainly KRT) using RNA sequencing [33]. Expression profiles of 40 primary extra-cranial malignant rhabdoid tumors, three human embryonic stem cell lines, and four fetal cerebellum samples were collected and screened for aberrantly expressed genes. Through compare RTs gene expression with genes expressed both in cell lines and fetal cerebellum samples, Author identified 398 up-regulated genes and 615 down-regulated ones. These genes may be used as diagnosis markers of MRT, but this study did not focus on 


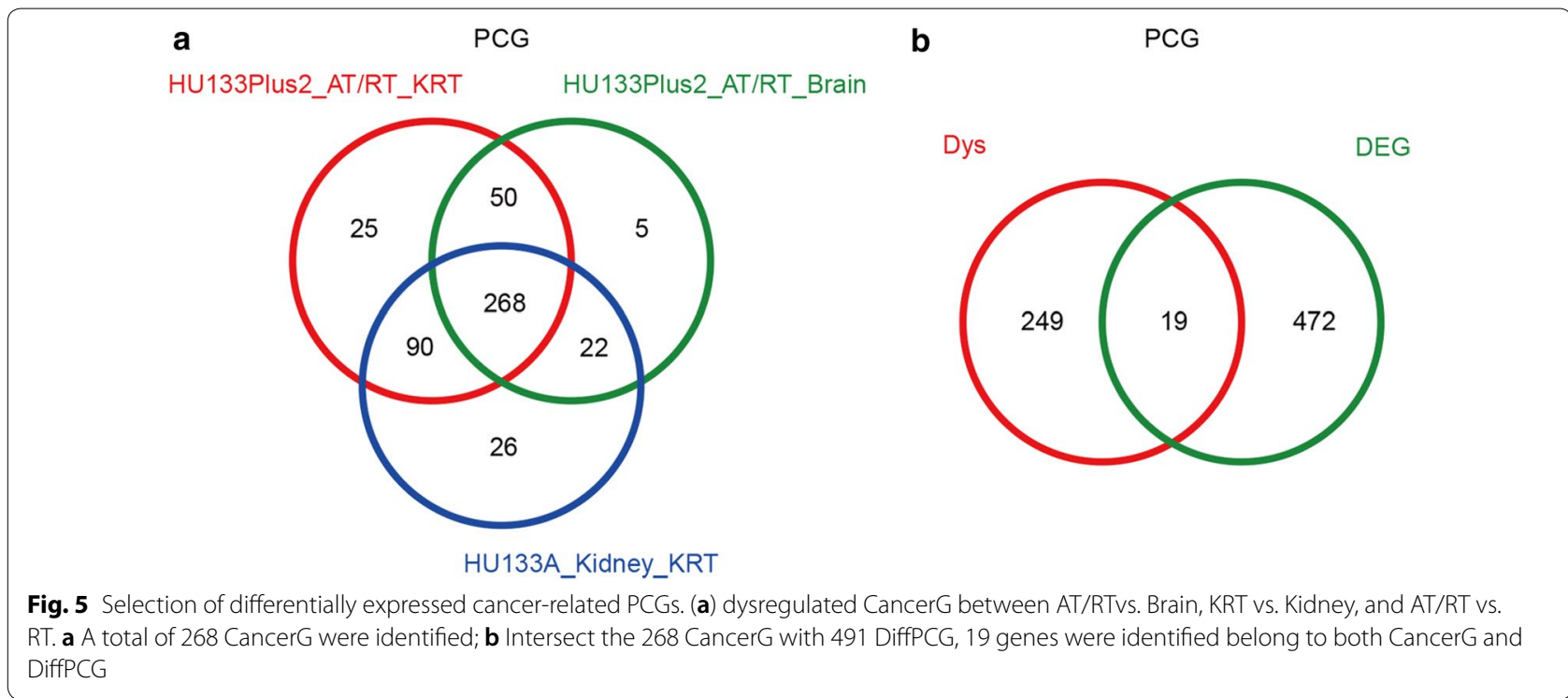

Table 3 List of 19 cancer-related PCGs that showed significantly altered expression in AT/RT vs. Brain, KRT vs. Kidney and KRT vs. AT/RT

\begin{tabular}{lr}
\hline Symbol & Entrezgene \\
\hline ATIC & 471 \\
DDB2 & 1643 \\
FANCA & 2175 \\
GNAS & 2778 \\
NONO & 4841 \\
NPM1 & 4869 \\
PBRM1 & 55,193 \\
PCM1 & 5108 \\
PDE4DIP & 653,513 \\
PTEN & 5728 \\
RPL10 & 6134 \\
RPL22 & 6146 \\
RPL5 & 6125 \\
SF3B1 & 23,451 \\
SMARCE1 & 6605 \\
SRSF3 & 6428 \\
SUZ12 & 23,512 \\
TCF3 & 6929 \\
ZMYM2 & 7750 \\
\hline
\end{tabular}

identifying marker candidates for KRT diagnosis. More specifically, similar investigations were conducted in AT/RT over the past few years. Based on patterns in the transcriptional profile, Torchia and colleagues [34] classified AT/RT into three subgroups with distinct genomic profiles, implicated cellular processes, and clinicopathological and survival features. These findings were consistent with those of an independent study [35]. All three reports, however, focused on the classification and prognosis and AT/RT. Chakravadhanula et al. [36] evaluated the performance of HOTAIR and HOXC as diagnostic markers of AT/RT, however, the authors found that both genes are not sufficient for distinguishing AT/RT from several other forms pediatric brain tumors. In an interesting study, Ho et al. [37] proposed three oncogenes, FGFR2, S100A4 and ERBB2 (HER2/neu), as markers for diagnosing AT/RT, based on the aberrant high expression in tissue samples expressing SMARCB1. Overexpression of these genes may be used as novel markers that complement the current criteria, lack of SMARCB1expression. However, as these results were derived from a limited number of samples, further research is warranted to validate these candidates.

Regulation of PCG expression have been known to occur through a number of mechanisms. Upstream regulators include microRNAs and lncRNAs. In an interesting study into the role of microRNAs in Grupenmacher et al. [38] analyzed the expression profiles of microRNA and PCGs in $13 \mathrm{AT} / \mathrm{RT}$ and $10 \mathrm{KRT}$ cases, as well as two human RT cell lines. They found 122 genes significantly differentially expressed between AT/RT and KRT, about $76.22 \%$ (93/122) of which down regulated in AT/ RT, which was in accordance with our result (Table 1). However, the authors reported a general lack significantly altered expressions in microRNAs between AT/RT and KRT, Therefore, we focused on elucidating the potential of significantly altered lncRNA expression in our investigation, rather than miRNA, as lncRNAs have recently been established as key regulators in cancer. Through identifying differentially expression lncRNAs and constructing lncRNA-PCG co-expression network, 19 PCGs were selected based on co-expression relationship. 
Table 4 The dysregulated co-expression pairs retrieved for the 19 PCGs, and the number of the corresponding co-expressed IncRNA (namely "degree")

\begin{tabular}{|c|c|c|c|c|c|}
\hline AT/RT vs. KRT & Degree & AT/RT vs. Brain & Degree & KRT vs. Kidney & Degree \\
\hline ATIC & 5 & ATIC & 6 & GNAS & 7 \\
\hline FANCA & 7 & GNAS & 13 & NONO & 7 \\
\hline NONO & 7 & NONO & 19 & NPM1 & 10 \\
\hline NPM1 & 11 & PBRM1 & 21 & PBRM1 & 8 \\
\hline PBRM1 & 6 & PCM1 & 6 & PCM1 & 13 \\
\hline PCM1 & 8 & PDE4DIP & 11 & PTEN & 11 \\
\hline PDE4DIP & 9 & PTEN & 15 & RPL10 & 11 \\
\hline PTEN & 13 & RPL10 & 9 & RPL22 & 12 \\
\hline RPL10 & 7 & RPL5 & 6 & RPL5 & 14 \\
\hline RPL5 & 8 & SF3B1 & 26 & SF3B1 & 12 \\
\hline SF3B1 & 13 & SUZ12 & 21 & SRSF3 & 5 \\
\hline SMARCE1 & 5 & ZMYM2 & 26 & TCF3 & 7 \\
\hline SRSF3 & 6 & RPL22 & 4 & ZMYM2 & 12 \\
\hline SUZ12 & 5 & NPM1 & 3 & DDB2 & 3 \\
\hline TCF3 & 8 & DDB2 & 2 & PDE4DIP & 3 \\
\hline ZMYM2 & 13 & SRSF3 & 2 & SMARCE1 & 3 \\
\hline RPL22 & 4 & TCF3 & 2 & SUZ12 & 2 \\
\hline GNAS & 2 & FANCA & 1 & ATIC & 1 \\
\hline DDB2 & 1 & SMARCE1 & 1 & FANCA & 1 \\
\hline
\end{tabular}

Further screening, based on numbers of co-expressing lncRNAs, provided a final list of eight candidate markers.

Both RPL5 and RPL10 encode members of the 60S subunit of the ribosome $[39,40]$. The protein expression of both genes is relative low in the normal brain [41]. RPL5 binds $5 \mathrm{~S}$ rRNA and forms a stable complex, the $5 \mathrm{~S}$ ribonucleo protein particle, which is necessary for the $5 \mathrm{~S}$ rRNA transport, where cytoplasmic $5 \mathrm{~S}$ rRNA is transported to the nucleolus to be assembled into ribosomes. RPL5 may inhibit tumorigenesis through the activation of downstream tumor suppressors and the down-regulation of oncoprotein expression. A study showed that impaired ribosomes induce a p53-dependent cell cycle arrest [42]. RPL5 has also been reported to play tumor suppressor roles in breast tumors [43].

The functions and significance of RPL10 is largely unknown so far. Existing literature mainly focused on its association with autism and is still in debate [44, 45].
There is one report implicating RPL10 in T cell acute lymphoblastic leukemia (T-ALLs). Exome sequencing analysis identified mutation of RPL5 and RPL10 in 12 of $122(9.8 \%)$ pediatric T-ALLs, with a recurrent mutation of Arg98 in RPL10 [46]. Together, these studies point to a potential role of RPL5 and RPL10 in tumorigenesis, although the relevance of both genes in the KRT and AR/ RT has not been elucidated.

In this study, we examined the transcriptome profiles to identify novel prognostic markers for RTs, a rare, lethal, mostly pediatric cancer. After identifying differentially expressed lncRNAs and PCGs, we found intense dysregulation in lncRNA-PCG co-expressed pairs in AT/ RT and KRT. Among the key cancer-related PCGs in the co-expression network, RPL5 and RPL10 showed high levels of sensitivity and specificity AT/RT and KRT. After comparison with other common pediatric tumors, RPL5 and RPL10 can also be used to distinguish AT/RT from 

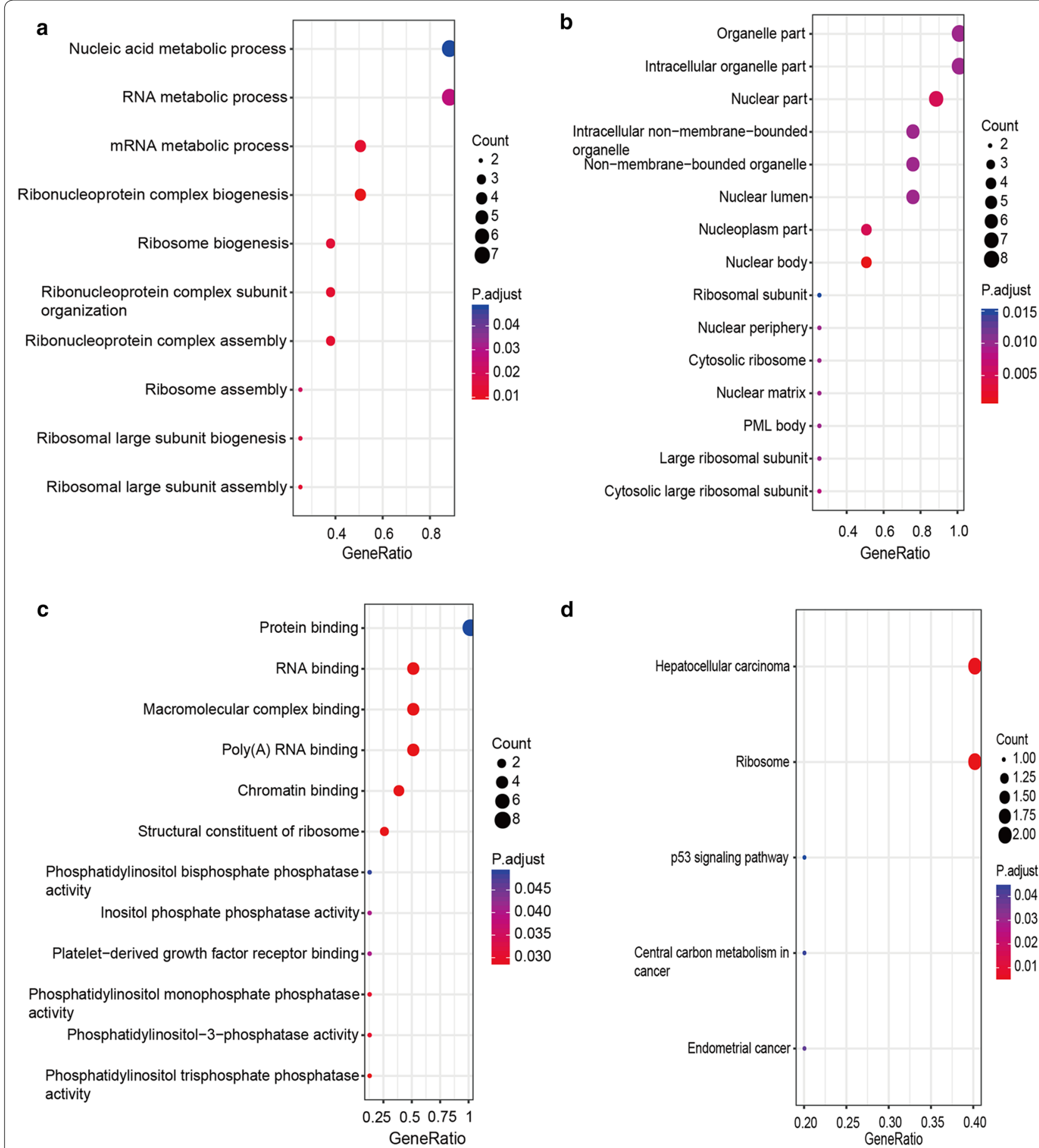

d

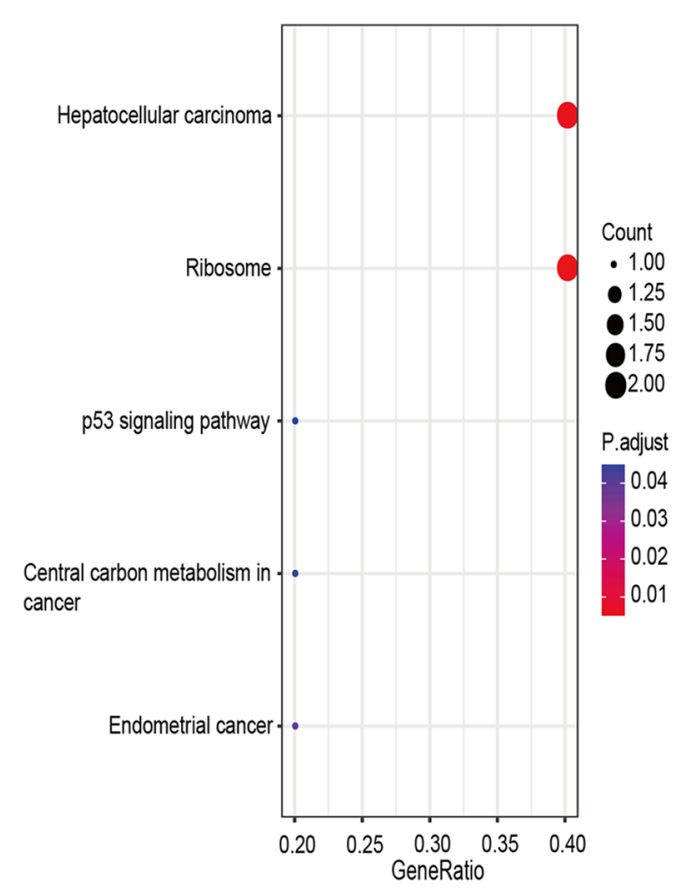

Fig. 6 KEGG pathway and GO enrichment of the eight differentially expressed cancer-related PCGs. a Enriched GO terms related to biological process, $\mathbf{b}$ enriched $\mathrm{GO}$ terms related to cellular components, $\mathbf{c}$ enriched $\mathrm{GO}$ terms related to molecular functions, and $\mathbf{d}$ enriched KEGG pathways

(See figure on next page.)

Fig. 7 ROC analysis of assessing the performance of RPL 5 and RPL10 as diagnostic markers of AT/RT and KRT. The left column shows ROC analysis of RPL5 in diagnosing a KRT, c AT/RT, and e distinguishing AT/RT from KRT. The right column shows ROC analysis of RPL10 in diagnosing $\mathbf{b}$ KRT, d AT/ RT, and $\mathbf{f}$ distinguishing AT/RT from KRT 
a

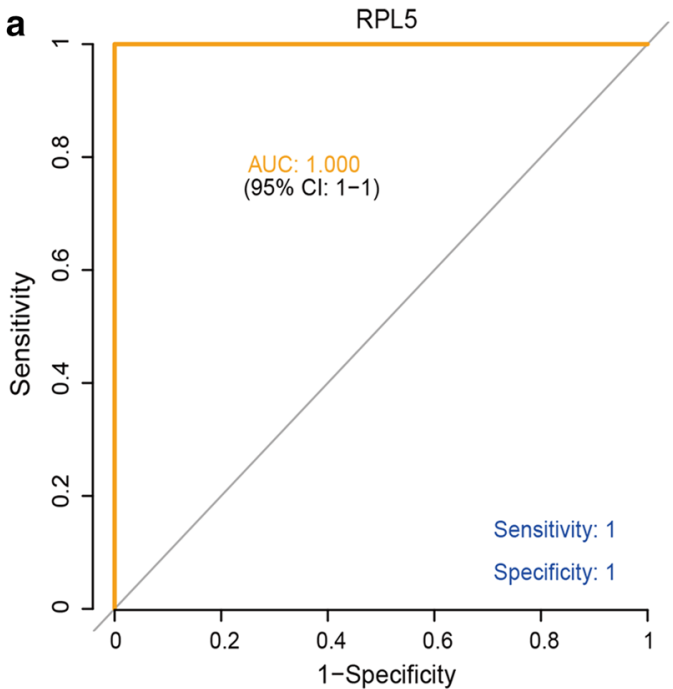

C
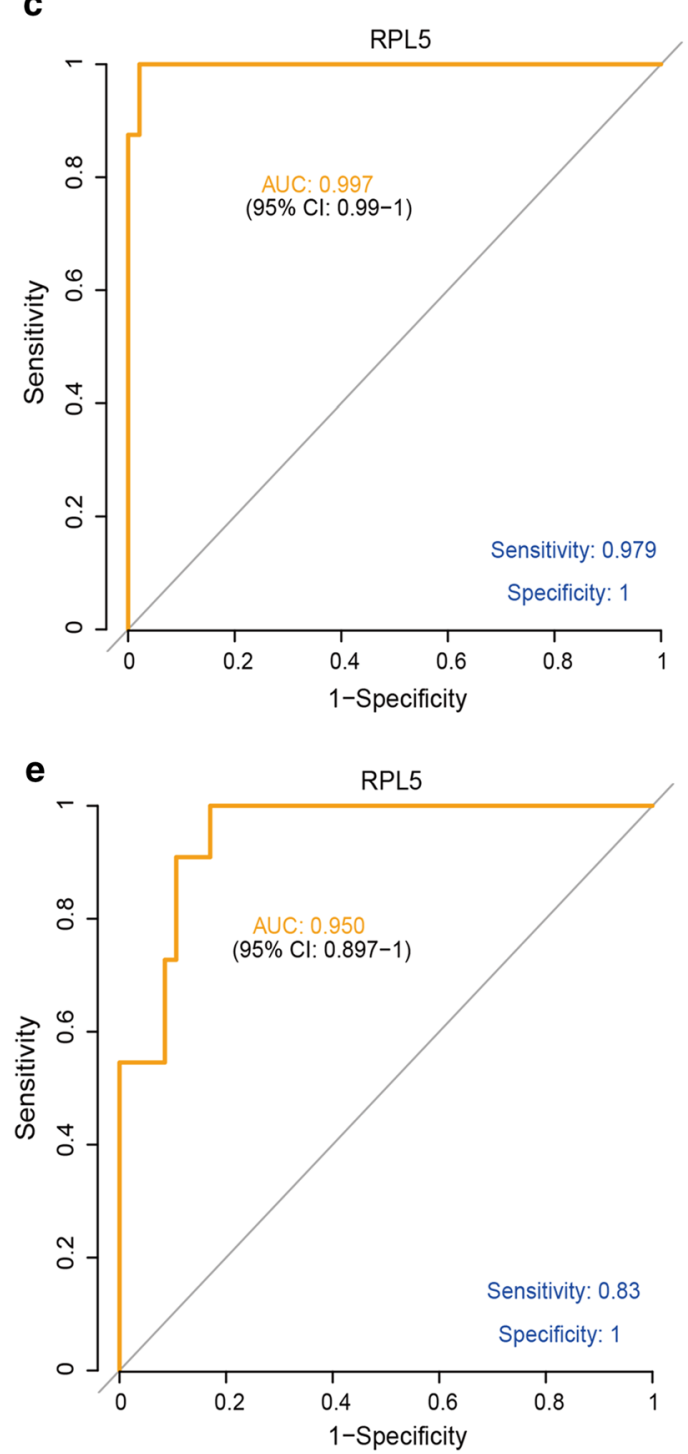

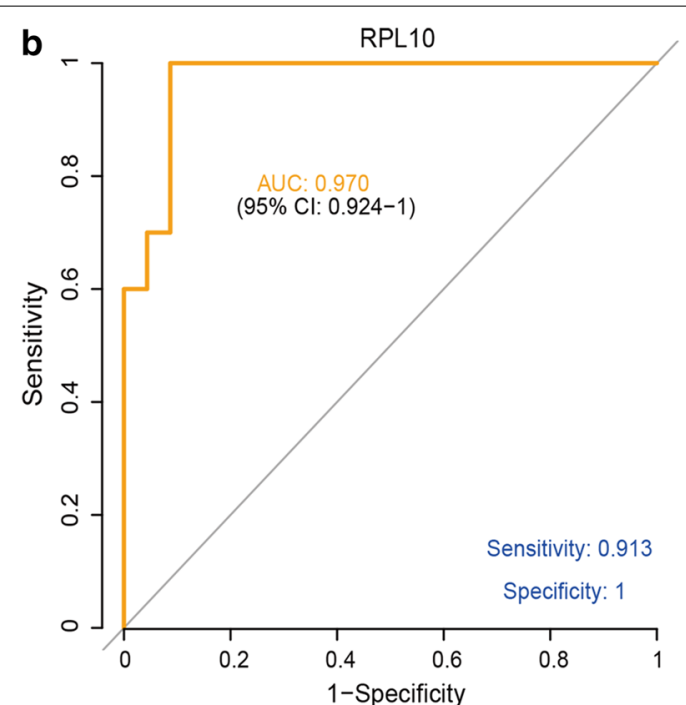

d
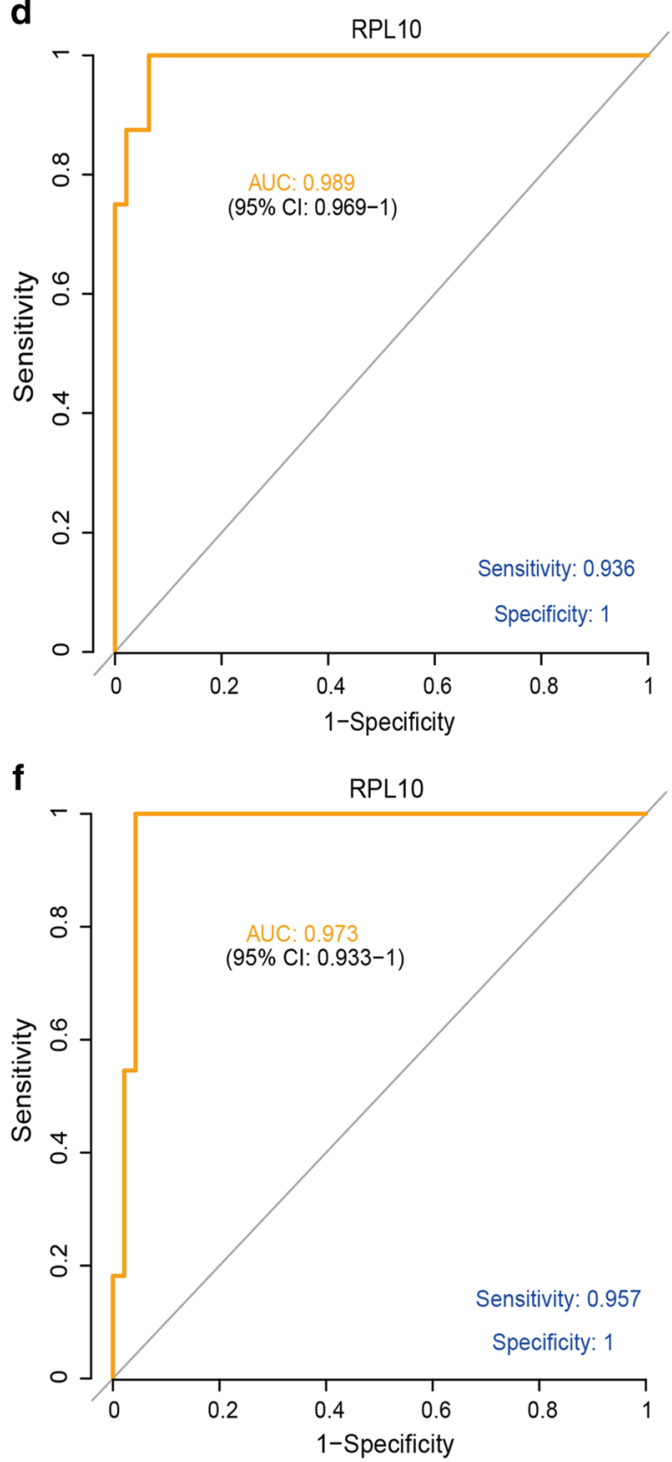

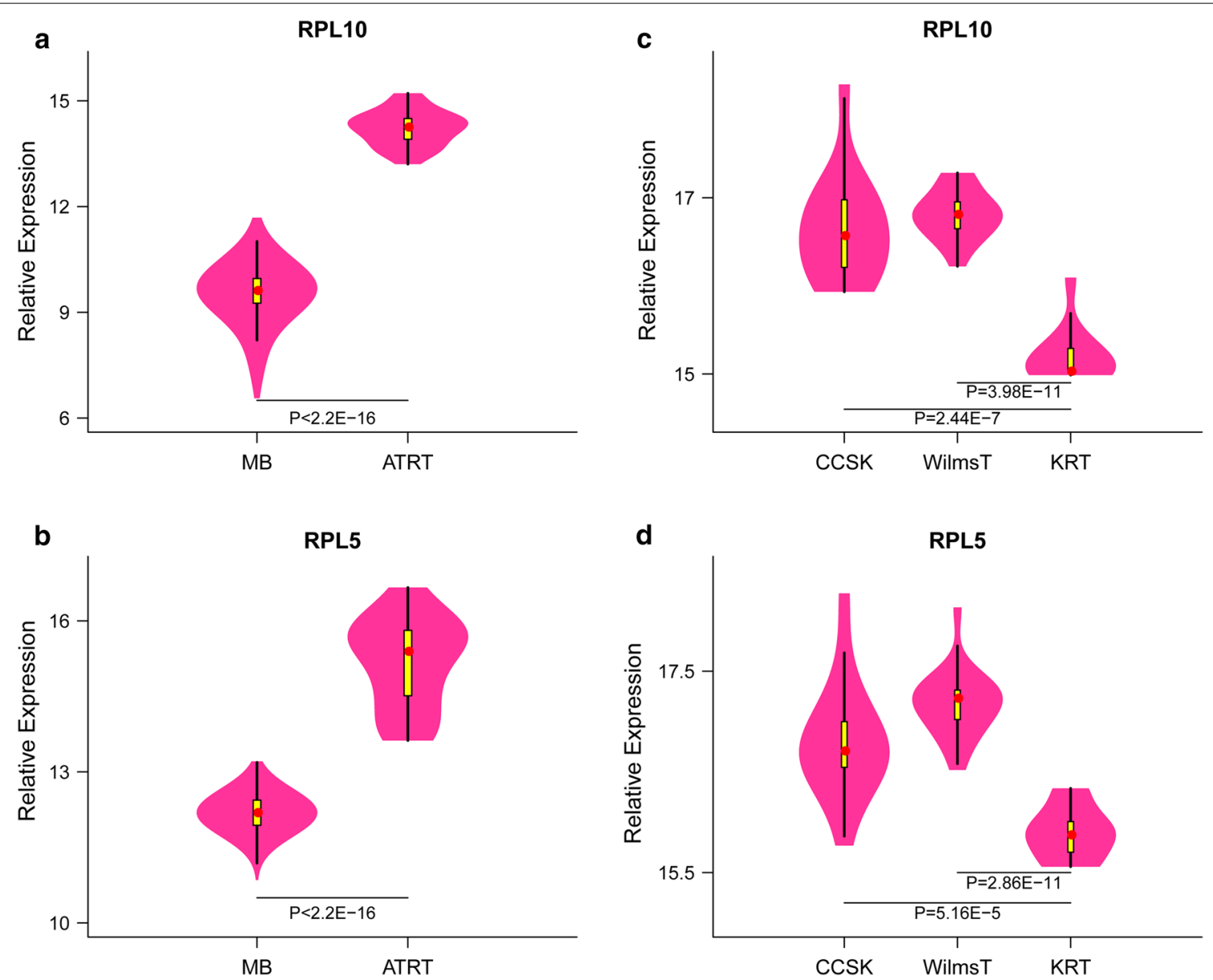

Fig. 8 RPL5/10 expression between AT/RT and medulloblastoma (a, b), KRT, Wilm's tumor and clear cell sarcoma of the kidney (c, d)

medulloblastoma. To our knowledge, this study is the first in associating RPL5 and RPL10 with AT/RT diagnosis. Our results therefore identify two novel promising diagnostic markers for AT/RT, and provide the basis for work to further assess the performance, and to develop a robust diagnosis practice using these markers.

\section{Conclusions}

Our study mined existing GEO datasets for novel diagnostic markers associated with Rhabdoid tumors, and identified RPL5 and RPL10 as potential diagnostic markers for AT/RT. These two biomarkers may be used as supplementary biomarkers to canonical diagnostic tools such as biopsy and immunohistochemistry. Further research is warranted to characterize the roles and significance of RPL5 and RPL10 in AT/RT.

\section{Additional files}

Additional file 1: Table S1. Datasets of the 47 AT/RTs, 31 KRTs, 8 normal brain samples and 23 normal kidney samples.

Additional file 2: Figure S1. An overview of PCGs used in this study. There were a total of 12831 PCGs in the microarray profiles (denoted AllPCG), among which 491 differentially expressed PCGs AT/RT vs. Brain, KRT vs. Kidney and KRT vs. AT/RT (denoted DiffPCG). DiffPCGs that have been reported to be strongly associated with cancer (denoted CancerG) were highlighted and provide a pool of candidate diagnostic markers.

Additional file 3: Figure S2. Relative expression levels of RPL5 (A, B, and C) and RPL10 (D, E, and F) in AT/RT vs. Brain, KRT vs. Kidney and KRT vs. AT/ RT.

\section{Abbreviations}

RT: rhabdoid tumors; AT/RT: Atypical teratoid/rhabdoid tumors; KRT: kidney rhabdoid tumors; PCG: protein coding gene; IncRNA: long non-coding RNA; ROC: receiver operating characteristic; MB: medulloblastoma; CCSK: clear cell sarcoma of the kidney. 


\section{Authors' contributions}

YR and CT designed the work and contributed equally to the work, XW did the statistical analysis. YJ supervised the work. All authors read and approved the final manuscript.

\section{Author details}

1 Department of Neurosurgery, West China Hospital of Sichuan University, No. 37 Guo Xue Xiang, Chengdu, Sichuan, China. ${ }^{2}$ Beijing Institute of Genomics, Chinese Academy of Sciences, Beijing, China.

\section{Acknowledgements}

We thank all the doctors in our department for their help in patients care so that we can have enough time to conduct this study.

\section{Competing interests}

The authors declare that they have no competing interests.

\section{Availability of data and materials}

The data of this manuscript can be download from the NCBI GEO database.

\section{Content of publication}

Not applicable.

\section{Ethical approval and consent to participate}

Not applicable.

\section{Funding}

Not applicable.

\section{Publisher's Note}

Springer Nature remains neutral with regard to jurisdictional claims in published maps and institutional affiliations.

Received: 23 June 2018 Accepted: 8 November 2018

Published online: 20 November 2018

\section{References}

1. Beckwith JB, Palmer NF. Histopathology and prognosis of Wilms tumors: results from the First National Wilms'Tumor Study. Cancer. 1978:41(5):1937-48.

2. Haas JE, Palmer NF, Weinberg AG, Beckwith JB. Ultrastructure of malignant rhabdoid tumor of the kidney. A distinctive renal tumor of children. Hum Pathol. 1981;12(7):646-57.

3. Rorke LB, Packer RJ, Biegel JA. Central nervous system atypical teratoid/ rhabdoid tumors of infancy and childhood: definition of an entity. J Neurosurg. 1996:85(1):56-65.

4. Kleihues P, Louis DN, Scheithauer BW, Rorke LB, Reifenberger G, Burger PC, Cavenee WK. The WHO classification of tumors of the nervous system. J Neuropathol Exp Neurol. 2002;61(3):215-25 (discussion 226-219).

5. Brennan B, Stiller C, Bourdeaut F. Extracranial rhabdoid tumours: what we have learned so far and future directions. Lancet Oncol. 2013;14(8):e329-36

6. Rickert $\mathrm{CH}$, Paulus W. Epidemiology of central nervous system tumors in childhood and adolescence based on the new WHO classification. Childs Nerv Syst. 2001:17(9):503-11.

7. Wong TT, Ho DM, Chang KP, Yen SH, Guo WY, Chang FC, Liang ML, Pan HC, Chung WY. Primary pediatric brain tumors: statistics of Taipei VGH, Taiwan (1975-2004). Cancer. 2005;104(10):2156-67.

8. Kaderali Z, Lamberti-Pasculli M, Rutka JT. The changing epidemiology of paediatric brain tumours: a review from the Hospital for Sick Children. Childs Nerv Syst. 2009;25(7):787-93.

9. Ostrom QT, Chen Y, M. de Blank P, Ondracek A, Farah P, Gittleman H, Wolinsky Y, Kruchko C, Cohen ML, Brat DJ, et al. The descriptive epidemiology of atypical teratoid/rhabdoid tumors in the United States, 2001 2010. Neuro-oncology. 2014;16(10):1392-9.

10. Parham DM, Weeks DA, Beckwith JB. The clinicopathologic spectrum of putative extrarenal rhabdoid tumors. An analysis of 42 cases studied with immunohistochemistry or electron microscopy. Am J Surg Pathol. 1994;18(10):1010-29.

11. Vujanic GM, Sandstedt B, Harms D, Boccon-Gibod L, Delemarre JF. Rhabdoid tumour of the kidney: a clinicopathological study of 22 patients from the International Society of Paediatric Oncology (SIOP) nephroblastoma file. Histopathology. 1996;28(4):333-40.

12. Biegel JA, Tan L, Zhang F, Wainwright L, Russo P, Rorke LB. Alterations of the hSNF5/INI1 gene in central nervous system atypical teratoid/rhabdoid tumors and renal and extrarenal rhabdoid tumors. Clin Cancer Res. 2002;8(11):3461-7.

13. Le Loarer F, Zhang L, Fletcher CD, Ribeiro A, Singer S, Italiano A, Neuville A, Houlier A, Chibon F, Coindre JM, et al. Consistent SMARCB1 homozygous deletions in epithelioid sarcoma and in a subset of myoepithelial carcinomas can be reliably detected by FISH in archival material. Genes Chromosom Cancer. 2014;53(6):475-86.

14. Sullivan LM, Folpe AL, Pawel BR, Judkins AR, Biegel JA. Epithelioid sarcoma is associated with a high percentage of SMARCB1 deletions. Mod Pathol. 2013;26(3):385-92

15. Hasselblatt M, Oyen F, Gesk S, Kordes U, Wrede B, Bergmann M, Schmid H, Fruhwald MC, Schneppenheim R, Siebert R, et al. Cribriform neuroepithelial tumor (CRINET): a nonrhabdoid ventricular tumor with INI1 loss and relatively favorable prognosis. J Neuropathol Exp Neurol. 2009;68(12):1249-55.

16. Arnold MA, Stallings-Archer K, Marlin E, Grondin R, Olshefski R, Biegel JA, Pierson CR. Cribriform neuroepithelial tumor arising in the lateral ventricle. Pediatr Dev Pathol. 2013;16(4):301-7.

17. Liu Q, Galli S, Srinivasan R, Linehan WM, Tsokos M, Merino MJ. Renal medullary carcinoma: molecular, immunohistochemistry, and morphologic correlation. Am J Surg Pathol. 2013;37(3):368-74.

18. Calderaro J, Moroch J, Pierron G, Pedeutour F, Grison C, Maille P, Soyeux P, de la Taille A, Couturier J, Vieillefond A, et al. SMARCB1/INI1 inactivation in renal medullary carcinoma. Histopathology. 2012;61(3):428-35.

19. Mobley BC, McKenney JK, Bangs CD, Callahan K, Yeom KW, Schneppenheim R, Hayden MG, Cherry AM, Gokden M, Edwards MS, et al. Loss of SMARCB1/INI1 expression in poorly differentiated chordomas. Acta Neuropathol. 2010;120(6):745-53.

20. Biegel JA. Molecular genetics of atypical teratoid/rhabdoid tumor. Neurosurg Focus. 2006;20(1):E11.

21. Autio R, Kilpinen S, Saarela M, Kallioniemi O, Hautaniemi S, Astola J. Comparison of Affymetrix data normalization methods using 6,926 experiments across five array generations. BMC Bioinformatics. 2009;10(Suppl 1):S24.

22. Basavarajappa BS. Neuropharmacology of the endocannabinoid signaling system-molecular mechanisms, biological actions and synaptic plasticity. Curr Neuropharmacol. 2007;5(2):81-97.

23. Ohno-Shosaku T, Tanimura A, Hashimotodani Y, Kano M. Endocannabinoids and retrograde modulation of synaptic transmission. Neuroscientist. 2012;18(2):119-32.

24. Neve KA, Seamans JK, Trantham-Davidson H. Dopamine receptor signaling. J Recept Signal Transduct Res. 2004;24(3):165-205.

25. Beaulieu JM, Gainetdinov RR. The physiology, signaling, and pharmacology of dopamine receptors. Pharmacol Rev. 2011;63(1):182-217.

26. Ferraguti F, Crepaldi L, Nicoletti F. Metabotropic glutamate 1 receptor: current concepts and perspectives. Pharmacol Rev. 2008;60(4):536-81.

27. Niswender CM, Conn PJ. Metabotropic glutamate receptors: physiology, pharmacology, and disease. Annu Rev Pharmacol Toxicol. 2010;50:295-322

28. Resende RR, Adhikari A. Cholinergic receptor pathways involved in apoptosis, cell proliferation and neuronal differentiation. Cell Commun Signal. 2009;7:20.

29. Brown DA. Muscarinic acetylcholine receptors (mAChRs) in the nervous system: some functions and mechanisms. J Mol Neurosci. 2010;41(3):340-6.

30. Ben-Ari Y, Khazipov R, Leinekugel X, Caillard O, Gaiarsa JL. GABAA, NMDA and AMPA receptors: a developmentally regulated 'menage a trois.' Trends Neurosci. 1997;20(11):523-9.

31. Farrant M, Kaila K. The cellular, molecular and ionic basis of GABA(A) receptor signalling. Prog Brain Res. 2007;160:59-87.

32. Uhlen M, Fagerberg L, Hallstrom BM, Lindskog C, Oksvold P, Mardinoglu A, Sivertsson A, Kampf C, Sjostedt E, Asplund A, et al. Proteomics. Tissuebased map of the human proteome. Science. 2015:347(6220):1260419. 
33. Chun HJ, Lim EL, Heravi-Moussavi A, Saberi S, Mungall KL, Bilenky M, Carles A, Tse K, Shlafman I, Zhu K, et al. Genome-wide profiles of extra-cranial malignant rhabdoid tumors reveal heterogeneity and dysregulated developmental pathways. Cancer Cell. 2016;29(3):394-406.

34. Torchia J, Picard D, Lafay-Cousin L, Hawkins CE, Kim SK, Letourneau L, Ra YS, Ho KC, Chan TS, Sin-Chan P, et al. Molecular subgroups of atypical teratoid rhabdoid tumours in children: an integrated genomic and clinicopathological analysis. Lancet Oncol. 2015;16(5):569-82.

35. Johann PD, Erkek S, Zapatka M, Kerl K, Buchhalter I, Hovestadt V, Jones DT, Sturm D, Hermann C, Segura Wang M, et al. Atypical teratoid/rhabdoid tumors are comprised of three epigenetic subgroups with distinct enhancer landscapes. Cancer Cell. 2016;29(3):379-93.

36. Chakravadhanula M, Ozols W, Hampton CN, Zhou L, Catchpoole D, Bhardwaj RD. Expression of the HOX genes and HOTAIR in atypical teratoid rhabdoid tumors and other pediatric brain tumors. Cancer Genet. 2014;207(9):425-8.

37. Ho DM, Shih CC, Liang ML, Tsai CY, Hsieh TH, Tsai CH, Lin SC, Chang TY, Chao ME, Wang HW, et al. Integrated genomics has identified a new AT/ RT-like yet INI1-positive brain tumor subtype among primary pediatric embryonal tumors. BMC Med Genomics. 2015:8:32

38. Grupenmacher AT, Halpern AL, Bonaldo Mde F, Huang CC, Hamm CA, de Andrade A, Tomita T, Sredni ST. Study of the gene expression and microRNA expression profiles of malignant rhabdoid tumors originated in the brain (AT/RT) and in the kidney (RTK). Childs Nerv Syst. 2013;29(11):1977-83.

39. Qu LH, Nicoloso M, Michot B, Azum MC, Caizergues-Ferrer M, Renalier $\mathrm{MH}$, Bachellerie JP. U21, a novel small nucleolar RNA with a $13 \mathrm{nt}$. complementarity to $28 \mathrm{~S}$ rRNA, is encoded in an intron of ribosomal protein L5 gene in chicken and mammals. Nucleic Acids Res. 1994;22(20):4073-81.
40. Frigerio JM, Dagorn JC, lovanna JL. Cloning, sequencing and expression of the L5, L21, L27a, L28, S5, S9, S10 and S29 human ribosomal protein mRNAs. Biochem Biophys Acta. 1995;1262(1):64-8.

41. Fagerberg L, Hallstrom BM, Oksvold P, Kampf C, Djureinovic D, Odeberg J, Habuka M, Tahmasebpoor S, Danielsson A, Edlund K, et al. Analysis of the human tissue-specific expression by genome-wide integration of transcriptomics and antibody-based proteomics. Mol Cell Proteomics. 2014;13(2):397-406

42. Teng T, Mercer CA, Hexley P, Thomas G, Fumagalli S. Loss of tumor suppressor RPL5/RPL11 does not induce cell cycle arrest but impedes proliferation due to reduced ribosome content and translation capacity. Mol Cell Biol. 2013:33(23):4660-71.

43. Fancello L, Kampen KR, Hofman IJ, Verbeeck J, De Keersmaecker K. The ribosomal protein gene RPL5 is a haploinsufficient tumor suppressor in multiple cancer types. Oncotarget. 2017;8(9):14462-78.

44. Chiocchetti A, Pakalapati G, Duketis E, Wiemann S, Poustka A, Poustka F, Klauck SM. Mutation and expression analyses of the ribosomal protein gene RPL10 in an extended German sample of patients with autism spectrum disorder. Am J Med Genet A. 2011;155A(6):1472-5.

45. Gong X, Delorme R, Fauchereau F, Durand CM, Chaste P, Betancur C, Goubran-Botros H, Nygren G, Anckarsater H, Rastam M, et al. An investigation of ribosomal protein $\mathrm{L} 10$ gene in autism spectrum disorders. BMC Med Genet. 2009;10:7.

46. De Keersmaecker K, Atak ZK, Li N, Vicente C, Patchett S, Girardi T, Gianfelici $V$, Geerdens E, Clappier E, Porcu M, et al. Exome sequencing identifies mutation in CNOT3 and ribosomal genes RPL5 and RPL 10 in T-cell acute lymphoblastic leukemia. Nat Genet. 2013:45(2):186-90.
Ready to submit your research? Choose BMC and benefit from:

- fast, convenient online submission

- thorough peer review by experienced researchers in your field

- rapid publication on acceptance

- support for research data, including large and complex data types

- gold Open Access which fosters wider collaboration and increased citations

- maximum visibility for your research: over 100M website views per year

At BMC, research is always in progress.

Learn more biomedcentral.com/submissions 